\title{
Allopurinol-induced hypersensitivity syndrome followed by painless thyroiditis in a patient with asymptomatic hyperuricemia
}

Xiaolin Chen, Yili Cai, Xin Ge

Department of Endocrinology, Renmin Hospital of Wuhan University, Wuhan, China

Submitted: 10 November 2018

Accepted: 19 February 2019

Arch Med Sci 2020; 16 (5): 1254-1256

DOI: https://doi.org/10.5114/aoms.2020.97971

Copyright @ 2020 Termedia \& Banach

Allopurinol, an inhibitor of xanthine oxidase, is a urate-lowering drug, which has been used to prevent recurrent gout and asymptomatic hyperuricemia. It is known that allopurinol causes hypersensitivity syndrome (HS), including drug rash with eosinophilia and systemic symptoms, Stevens-Johnson syndrome, and toxic epidermal necrolysis, which is related to cell-mediated immunity. Allopurinol-induced hypersensitivity syndrome (AIHS) is a life-threatening adverse reaction characterized by fever, skin rashes, eosinophilia, and liver and/or renal dysfunction. Limbic encephalitis, myocarditis, and gastrointestinal disease have also been reported to occur during the course of the disease. To date, there are no available data regarding the association of painless thyroiditis with AIHS. Here, we report the first case of painless thyroiditis associated with AIHS.

A 52-year-old man was admitted to the hospital with a 4-day history of high-grade fever, itch, maculopapular rash, and malaise. He had a history of hyperuricemia, and had started taking oral allopurinol (300 mg daily) 4 weeks previously. There was no personal or family history of thyroid or hepatic diseases, or drug allergies.

Following admission, the patient had fever (temperature $40^{\circ} \mathrm{C}$ ), with a blood pressure of $126 / 78 \mathrm{~mm} \mathrm{Hg}$, a pulse of 102 beats/min, and a respiration rate of 20 breaths/min. Physical examination revealed maculopapular rash involving almost $90 \%$ of the body surface. He had a grade 1 diffuse goiter. His chest sounds were normal.

The results of routine blood examinations are listed in Table I. The patient had elevated alanine aminotransferase (ALT), aspartate aminotransferase (AST), and creatinine levels. His leukocyte count was normal, but his eosinophil count was increased to 1.29 (normal $(\mathrm{N})$ : 0.02-0.52 $\left.\times 10^{9} / \mathrm{l}\right)$. Although his serum free triiodothyronine (fT3) and thyroxine (fT4) levels were normal, there was significant suppression of thyroid-stimulating hormone (TSH). Serology for viruses of hepatitis, human cytomegalovirus (HCMV), and Epstein-Barr virus (EBV) was negative. After consultation with a dermatologist, we considered a diagnosis of hypersensitivity syndrome induced by allopurinol. The intake of allopurinol was stopped. The human leukocyte antigen (HLA)-B locus genotyping was performed in the patient.

The patient received dexamethasone $5 \mathrm{mg}$ IV every day for 5 days. Glutathione was used to maintain physiological function of cells. At 15 days after treatment, his ALT, AST and creatinine levels had decreased to $62 \mathrm{U} / \mathrm{l}, 48 \mathrm{U} / \mathrm{l}$, and $88 \mathrm{\mu mol} / \mathrm{l}$ respectively. A repeated blood analy-

\author{
Corresponding author: \\ Xiaolin Chen \\ Department \\ of Endocrinology \\ Renmin Hospital \\ of Wuhan University \\ Jiefang Road 238 \\ Wuchang District \\ Wuhan 430060 \\ Hubei Province \\ China \\ E-mail: weed-2@163.com
}


sis revealed a normal number of eosinophils. No fever was detected and the maculopapular rash on his body disappeared. Genotyping showed the presence of the HLA allele $B^{\star} 5801$. This result supported the diagnosis of hypersensitivity syndrome induced by allopurinol [1].

However, after 4 weeks of treatment, the patient still presented malaise. We examined his blood thyroid hormones again. Serum fT3, fT4, and TSH concentrations were measured by the chemiluminescence assays (CLIA) method using a commercial kit (Bayer, Germany).

The intra-assay and inter-assay coefficient of variation values were as follows: $\mathrm{TSH}: 2.7 \%$ and 4.7\%, fT3: $3.4 \%$ and $5.5 \%$, fT $4: 2.4 \%$ and $4.2 \%$. His serum fT3 and fT4 levels were higher than 20.00 $\mathrm{pg} / \mathrm{ml}(\mathrm{N}: 2.3-4.2 \mathrm{pg} / \mathrm{ml})$ and $12.00 \mathrm{ng} / \mathrm{dl}$ (N: 0.89$1.8 \mathrm{ng} / \mathrm{dl})$ respectively, with a TSH of $0.011 \mu \mathrm{lU} / \mathrm{ml}$ ( $\mathrm{N}: 0.55-4.78 \mu \mathrm{lU} / \mathrm{ml})$. The thyroid-associated antibodies and thyroid ${ }^{131} \mathrm{I}$ uptake rate were tested as well. As listed in Table II, the levels of thyroid peroxidase (TPO), antithyroglobulin (TG), and thyroid-stimulating receptor (TR) antibodies were normal. The erythrocyte sedimentation rate (ESR) level was $73 \mathrm{~mm} / \mathrm{h}$ ( $\mathrm{N}: 0-21 \mathrm{~mm} / \mathrm{h})$. The thyroid ${ }^{131}$ I uptake rate was reduced. All these results suggested that the patient's thyroid dysfunction was not caused by thyroid autoantibodies. Thus, we considered that the thyroid dysfunction was caused by painless thyroiditis.

No therapeutic intervention was required for this patient. Follow-up was prescribed in the endocrinology clinic. Eight weeks after stopping taking allopurinol, the patient's fT3, f T4, TSH, and ESR were reduced to $3.74 \mathrm{pg} / \mathrm{ml}, 1.65 \mathrm{ng} / \mathrm{dl}$, $0.013 \mu \mathrm{lU} / \mathrm{ml}$ and $35 \mathrm{~mm} / \mathrm{h}$ respectively. After 4 more weeks, the patient's fT3, fT4 and ESR

Table I. Results of routine laboratory investigations

\begin{tabular}{|lc|}
\hline Test (normal value) & Result \\
\hline Leukocytes $\left(3.5-9.5 \times 10^{9} / \mathrm{l}\right)$ & $8.46 \times 10^{9} / \mathrm{l}$ \\
\hline Neutrophils $\left(1.8-6.3 \times 10^{9} / \mathrm{l}\right)$ & $4.97 \times 10^{9} / \mathrm{l}$ \\
\hline Eosinophils $\left(0.02-0.52 \times 10^{9} / \mathrm{l}\right)$ & $1.29 \times 10^{9} / \mathrm{l}$ \\
\hline Procalcitonin $(<0.1 \mathrm{ng} / \mathrm{ml})$ & $0.07 \mathrm{ng} / \mathrm{ml}$ \\
\hline ALT $(9-50 \mathrm{U} / \mathrm{l})$ & $302 \mathrm{U} / \mathrm{l}$ \\
\hline AST $(15-40 \mathrm{U} / \mathrm{l})$ & $105 \mathrm{U} / \mathrm{l}$ \\
\hline Creatinine $(57-97 \mu \mathrm{mol} / \mathrm{l})$ & $125 \mu \mathrm{mol} / \mathrm{l}$ \\
\hline eGFR $(>90 \mathrm{ml} / \mathrm{min})$ & $56.67 \mathrm{ml} / \mathrm{min}$ \\
\hline Uric acid $(208-428 \mu \mathrm{mol} / \mathrm{l})$ & $459 \mu \mathrm{mol} / \mathrm{l}$ \\
\hline Free T3 $(2.3-4.2 \mathrm{pg} / \mathrm{ml})$ & 3.60 \\
\hline Free T4 $(0.89-1.8 \mathrm{ng} / \mathrm{dl})$ & 0.084 \\
\hline TSH $(0.55-4.78 \mu \mathrm{lU} / \mathrm{ml})$ & \\
\hline Abnormal results are in bold. & \\
\hline
\end{tabular}

were further reduced to $1.64 \mathrm{pg} / \mathrm{ml}, 0.33 \mathrm{ng} / \mathrm{dl}$ and $14 \mathrm{~mm} / \mathrm{h}$ respectively. TSH was increased to $78.155 \mu \mathrm{IU} / \mathrm{ml}$. The thyroid ${ }^{131} \mathrm{I}$ uptake rate was $15.5 \%$ ( $2 \mathrm{~h}), 10.7 \%$ (4 h), and $16.1 \%$ (24 h). The patient was prescribed oral levothyroxine sodium $(50 \mu \mathrm{g} /$ daily). After 6 weeks of follow-up, thyroid function tests were re-checked in an outpatient department. The serum TSH, fT3 and fT4 were $1.993 \mathrm{\mu lU} / \mathrm{ml}, 3.5 \mathrm{pg} / \mathrm{ml}$, and $1.26 \mathrm{ng} / \mathrm{dl}$ respectively. Based on all these data, we diagnosed this patient as having hypothyroidism associated with painless thyroiditis due to AlHS.

In this case the presence of transient thyrotoxicosis, and hypothyroidism in the absence of thyroid-associated antibodies suggest an etiology of painless thyroiditis. Painless thyroiditis is an autoimmune thyroiditis. Its etiology is related to autoimmune and viral infection. In the present case, as the onset of painless thyroiditis occurred after the intake of oral allopurinol and drug-induced hypersensitivity syndrome (DIHS), we speculated that the AlHS might be responsible for painless thyroiditis. There have been several reports of painless thyroiditis induced by drugs such as tamoxifen citrate, and anti-programmed cell death 1 (PD-1) monoclonal antibody [2, 3]. Kano et al. reported that 2 of the 145 patients with DIHS/drug reaction with eosinophilia and systemic symptoms (DRESS) developed painless thyroids after recovery from DIHS/DRESS [4]. The mechanism of the pathogenic effect of AlHS on thyroid gland function is still unknown. A few reports have focused on the role of regulatory $T$ (Treg) cell-mediated immune response against drug antigens leading to a disorder involved in multiple organs [5]. Moreover, viral infection, such as viruses of HCMV,

Table II. Results of ESR, thyroid function and ${ }^{131}$ I uptake rate

\begin{tabular}{|lc|}
\hline Test (normal value) & Result \\
\hline Laboratory: & $73 \mathrm{~mm} / \mathrm{h}$ \\
\hline ESR $(0-21 \mathrm{~mm} / \mathrm{h})$ & $>20.00$ \\
\hline Free T3 $(2.3-4.2 \mathrm{pg} / \mathrm{ml})$ & 12.00 \\
\hline Free T4 $(0.89-1.8 \mathrm{ng} / \mathrm{dl})$ & 0.011 \\
\hline TSH $(0.55-4.78 \mu \mathrm{U} / \mathrm{ml})$ & $<28.00$ \\
\hline TPO antibody $(0-60 \mathrm{U} / \mathrm{ml})$ & 52.10 \\
\hline TG antibody $(0-60 \mathrm{U} / \mathrm{ml})$ & 0.46 \\
\hline TR antibody $(0-1.58 \mathrm{U} / \mathrm{l})$ & $10.7 \%$ \\
\hline Thyroid ${ }^{131}$ l uptake rate: & $1.8 \%$ \\
\hline 2-hour (10-30\%) & $0.1 \%$ \\
\hline $\begin{array}{l}\text { 4-hour (15-40\%) } \\
\text { 24-hour (25-60\%) }\end{array}$ \\
Abnormal results are in bold.
\end{tabular}


human herpesvirus 6 (HHV-6) and EB [6, 7], also plays an important role in DIHS. In the patients who developed painless thyroiditis after DIHS, HCMV-DNA and EBV-DNA were not detected in their urine and whole blood. That said, further investigations are warranted to clarify the physiological mechanisms of AlHS on thyroid gland function.

The HLA-B ${ }^{\star}$ 58:01 allele is a risk factor for AIHS [8]. HLA-B*58:01 is present in about $20 \%$ of certain Asian populations. HLA-B*58:01 was found in more than $90 \%$ of patients of Han Chinese with AlHS [9]. The HLA-B*58:01 allele had $95.20 \%$ sensitivity and $100 \%$ specificity for diagnosing allopurinol-related cutaneous adverse drug reactions (CADR) [10]. This strong association has also been reported in other studies $[11,12]$. Hence, routine testing of patients with hyperuricemia for HLA-B*58:01 could successfully reduce the occurrence of AlHS in Han Chinese populations.

In conclusion, our findings are compatible with a relationship between AIHS and painless thyroiditis. These findings also need to be confirmed by thorough retrospective analysis of patient cases with AIHS and painless thyroiditis. Clinicians who prescribe allopurinol should be aware of its potential risk for AlHS, especially in patients with the HLA-B*5801 allele. In addition, we would like to emphasize that careful long-term follow-up including thyroid hormone tests should be carried out in patients with DIHS/DRESS.

\section{Conflict of interest}

The authors declare no conflict of interest.

\section{References}

1. Cheng L, Zhang L, Gao L, Zhang W, Chen X, Zhou HH. Genotyping HLA-B*5801 for allopurinol-induced severe $\mathrm{cu}$ taneous adverse reactions: an accurate and prompt method. Clin Transl Sci 2015; 8: 834-6.

2. Watanobe $\mathrm{H}$, Kawabe $\mathrm{H}$. A case of painless thyroiditis possibly triggered by tamoxifen citrate, a synthetic antiestrogen. J Endocrinol Invest 1998; 21: 70-1.

3. Yamauchi I, Sakane Y, Fukuda Y, et al. Clinical features of nivolumab-induced thyroiditis: a case series study. Thyroid 2017; 27: 894-901.

4. Kano Y, Tohyama M, Aihara M, et al. Sequelae in 145 patients with drug-induced hypersensitivity syndrome/ drug reaction with eosinophilia and systemic symptoms: a survey conducted by the Asian Research Committee on Severe Cutaneous Adverse Reactions (ASCAR). J Dermatol 2015; 42: 276-82.

5. Chen C, Abe R, Pan R, et al. An updated review of the molecular mechanisms in drug hypersensitivity. J Immunol Res 2018; 2018: 6431694.

6. Miyashita K, Shobatake C, Miyagawa F, et al. Involvement of human herpesvirus 6 infection in renal dysfunction associated with DIHS/DRESS. Acta Derm Venereol 2016; 96: 114-5.

7. Ozcan D, Seçkin D, Bilezikçi B, Arslan H. The role of human herpesvirus-6, Epstein-Barr virus and cytomega- lovirus infections in the etiopathogenesis of different types of cutaneous drug reactions. Int I Dermatol 2010; 49: 1250-4.

8. Saksit N, Tassaneeyakul W, Nakkam N, et al. Risk factors of allopurinol-induced severe cutaneous adverse reactions in a Thai population. Pharmacogenet Genomics 2017; 27: 255-63.

9. Cheng L, Xiong Y, Qin CZ, et al. HLA-B*58:01 is strongly associated with allopurinol-induced severe cutaneous adverse reactions in Han Chinese patients: a multicentre retrospective case-control clinical study. $\mathrm{Br} J$ Dermatol 2015; 173: 555-8.

10. Sukasem C, Jantararoungtong T, Kuntawong P, et al. HLA-B (*)58:01 for allopurinol-induced cutaneous adverse drug reactions: implication for clinical interpretation in Thailand. Front Pharmacol 2016; 7: 186.

11. Jung JW, Song WJ, Kim YS, et al. HLA-B58 can help the clinical decision on starting allopurinol in patients with chronic renal insufficiency. Nephrol Dial Transplant 2011; 26: 3567-72.

12. Kang HR, Jee YK, Kim YS, et al. Positive and negative associations of HLA class I alleles with allopurinol-induced SCARs in Koreans. Pharmacogenet Genomics 2011; 21: 303-7. 